\title{
A PRÁTICA DE ENFERMAGEM BASEADA EM EVIDÊNCIAS. CONCEITOS E INFORMAÇÕES DISPONÍVEIS ONLINE
}

\author{
Maria Helena Larcher Caliri* \\ Maria Helena Palucci Marziale**
}

A investigação sistemática sobre a assistência de enfermagem no Brasil, tem evidenciado que em muitas áreas, os rituais, tradições e o conhecimento comum ainda prevalecem como embasamento para a prática apesar dos avanços obtidos na melhoria da formação profissional. Apesar do aumento no número de cursos de pós-graduação nos últimos anos, do número de enfermeiros pesquisadores e de artigos publicados, em muitas áreas, a assistência clínica parece não ter sido beneficiada dos conhecimentos produzidos.

O processo de implementação dos resultados da pesquisa envolve a produção de conhecimento, sua disseminação e utilização de forma a mudar a situação clínica. Na literatura internacional de enfermagem, diferentes modelos tem sido apresentados desde a década de 70, para facilitar a utilização dos resultados de pesquisa na prática.

O projeto CURN (Conduct and Utilization of Research in Nursing), um dos primeiros modelos desenvolvido por um grupo de enfermeiras da Associação de Enfermeiras de Michigan, destacou que a utilização da pesquisa na prática é um processo organizacional e que é necessário um ambiente institucional que estimule e dê suporte aos esforços dos profissionais para a observação de mudanças (CRANE, 1995).

O modelo proposto por STETLER defende que o processo de utilização dos resultados de pesquisa na prática deve ser visto tanto como um processo organizacional como individual sendo imperativo desenvolver nos enfermeiros o conhecimento, as habilidades e os valores considerados essenciais para que tenham pensamento crítico e reflexivo para direcionarem a sua prática (CRANE, 1995).
No final da década de 80 , a questão da avaliação da qualidade do cuidado prestado e a contenção dos gastos em saúde nos Estados Unidos impulsionaram as instituições, apoiadas pelo governo, a estudarem os resultados da assistência e o desenvolvimento de indicadores de qualidade e programas de melhoria de qualidade. O modelo da Universidade de IOWA foi desenvolvido neste contexto, visando infundir os resultados da pesquisa na prática e melhorar a qualidade do cuidado em aspectos identificados como problemáticos nas situações clínicas (TITLER et al., 1994).

Nos últimos anos, observamos que, nos eventos científicos e nas publicações internacionais na área de enfermagem, o conceito de "prática baseada em evidência (PBE)" tem recebido atenção de pesquisadores, educadores e enfermeiros assistenciais.

STETLER et al. (1998), definem a prática baseada em evidências como uma abordagem para a enfermagem que utiliza os resultados de pesquisa, o consenso entre especialistas conhecidos e a experiência clínica confirmada como bases para a prática clínica ao invés de experiências isoladas e não sistemáticas, rituais e opiniões sem fundamentação.

Para MADIGAN (1998), o conceito de PBE surgiu no Canadá na área da medicina, como uma abordagem para resolução de problemas no ensino clínico e logo após foi incorporada pelo Sistema Nacional de Saúde do Reino Unido. Nos Estados Unidos, o conceito foi utilizado por agências governamentais para criar diretrizes e nortear políticas de assistência em diversas áreas, para fornecer direcionamento aos profissionais sobre uma variedade de condições cronicas e agudas prevalentes no país.

* Enfermeira. Professor Doutor do Departamento de Enfermagem Geral e Especializada da Escola de Enfermagem de Ribeirão Preto da Universidade de São Paulo

** Enfermeira. Professor Livre-Docente do Departamento de Enfermagem Geral e Especializada da Escola de Enfermagem de Ribeirão Preto da Universidade de São Paulo 
A revolução da informática com o desenvolvimento da "World Wide Web" permitiu a constituição de Centros de Disseminação de Evidências em diferentes países nas últimas décadas, visando a globalização do conhecimento com diminuição das diferenças observadas na assistência. O projeto "Cochrane Library" envolve pesquisadores do mundo todo inclusive do Brasil (MEDICINA BASEADA EM EVIDÊNCIAS, 1999) e disponibiliza através da Internet, revisões da literatura para fundamentação da prática clínica. O "Centre for Evidence Based Nursing" da Universidade de York no Reino Unido é responsável pelas revisões sistemáticas em diversas áreas da enfermagem como parte da "Cochrane Library" (UNIVERSITY OF YORK, 1999).

Atualmente existe uma grande variedade de fontes de informações de evidências para a prática clínica de enfermagem, seja através de revistas especializadas online com acesso por assinatura ou sites gratuitos mantidos por instituições governamentais ou associações. Alguns sites são extremamente úteis pois além da revisões integrativas da literatura em temas específicos, fornecem exemplos de protocolos com base

\section{REFERÊNCIAS BIBLIOGRÁFICAS}

01. CRANE, J. The future of research utilization. Nursing Clinics of North America, v. 30, n. 3, p. 565-577, 1995.

02. MADIGAN, E.A. Evidence - based practice in homehealth care: a springboard for discussion. Home Health Care Nurse, v. 16, n. 6, p. 411415, 1998.

03. MEDICINA BASEADA EM EVIDÊNCIAS http:/ /www.epm.br/cochrane/ebm.htm em evidências e podem facilitar o trabalho do enfermeiro desenvolvendo pesquisas, ensino ou que busca formas de modificar a sua prática, necessitando porém a sua adequação à realidade antes da implementação e avaliação. A seguir apresentamos alguns destes endereços:

Evidence-based nursing http://www.bmjpg.com/data/ ebn.htm

The best practice network http://ww1.best4heath.org/ solutions/tools/index/cfm

The Online Journal of Clinical Innovations http:// www.cinahl.com

The Online Journal for Knowledge Synthesis for Nursing http://www.nursingsociety.org/library

Sigma Theta Tau's Online Literature Review for Nursing http://nursingsociety.org.online

$\mathrm{Na}$ Escola de Enfermagem de Ribeirão Preto:

Diretrizes para a prática - Prevenção e tratamento de úlcera de pressão http://www.eerp.usp.br/projetos/ ulcera

Diretrizes para a prática - Movimentação e transferência de pacientes acamados utilizando os princípios da ergonomia. http://www.eerp.usp.br/projetos/movpac

04. STETLER, C.B. et al., Evidence-based practice and the role of nursing leadership. JONA, v. 28, n. 7-8, p. 45-53, 1998.

05. THE UNIVERSITY OF YORK - NHS Centre for Reviews and Dissemination. Captado na Internet em 18/8/99. http://www.york.ac.uk/ depts/projects.htm

06. TITLER, M.G.; KLEIBER, C.; STEELMAN, V. et al. - Infusing research into practice to promote quality care. Nursing Research, v. 43, n. 5 p. 307-313, 1994. 